\title{
Experimental Investigation of Lifted Spray Flame with Preheated Coflow Condition
}

\author{
Kapil S. Sawankar* and Umesh G. Potdar \\ Department of Mechanical Engineering, Savitribai Phule Pune University, Maharashtra, India
}

Accepted 15 June 2016, Available online 20 June 2016, Special Issue-5 (June 2016)

\begin{abstract}
Liquid fuel currently provides the energy used by a variety of power systems such as industrial furnaces and boilers, as well as automotive and aerospace engines. Understanding the physical phenomena that control spray combustion processes is important because, as most of the practical combustion devices initially apply the fuel as a multi-phase flow. Applications such as industrial furnace, small capacity boilers, jet propulsion, and gas turbine combustion all utilize liquid fuels. This broad application motivates a fundamental research of the mechanisms that control spray flame behaviour. Issues such as flame structure, stabilization, and blow-off condition are important aspects of spray combustion that has to be understood for the wide variety of combustors that exist. In the present study, experimental work has been carried out for three different cases i.e. No coflow condition, normal coflow condition and preheated coflow condition. It has been observed that the flame lift-off is directly proportional to injection pressure, spray ejection velocity, mass flow rate of fuel and coflow velocity but inversely proportional to coflow temperature. Spray injectors are used to inject the fuel with mass flow rate varies from $1.8 \mathrm{Kg} / \mathrm{hr}$ to $7.4 \mathrm{Kg} / \mathrm{hr}$.
\end{abstract}

Keywords: Droplets, Lift-off Height, Coflow, Spray Combustion.

\section{Introduction}

Combustion is process in which the fuel is oxidized and large amount of heat energy is released. From the $1^{\text {st }}$ and $2^{\text {nd }}$ energy crises happened in 1980's and 1990's respectively, it has been observed that because of the continuous pollutant emission from the combustion of fossil fuel, the researchers have been continuously trying to develop the process of combustion in such a way that there should be reduction of $\mathrm{NO}_{\mathrm{x}}$ and $\mathrm{CO}$ emission and other unburned hydrocarbon.

There are main three types of fuel are exist in the world i.e. solid, liquid and gaseous fuel. Among all these three types of fuel there are several work on combustion of gaseous fuel has been carried out but very few works on combustion of liquid fuels are carried out.

According to Eva gutheil Liquid fuels, which are frequently used in practical combustion systems such as internal combustion engines, gas turbines and liquid-fueled rockets make a significant contribution towards present-day energy suppliers. Normally liquid fuel delivered into the combustion chamber as a turbulent spray, the character of which determines not only combustion efficiency and stability but also pollutants formation. Hence it is of major interest that

*Corresponding author: Kapil S. Sawankar turbulent spray combustion systems need to be well understood.

The investigation of the lifted spray flame is important to understand the flame dynamics and flame performance under different pressure and injection velocity range inside the dump combustors, such as liquid fuel based ramjets, gas turbines, and rocket combustors .

The aforementioned studies clearly show the practical importance of the technology, however, many aspects in the near-injector region are not investigated. In the spray region, the fuel stream first has to be shattered into an ensemble of droplets with a desirable distribution of sizes and velocities in order to achieve the required rate of vaporization, chemical heatrelease, levels of conversion and pollutant emissions.

Instabilities at the liquid gas interface in the near atomizer region lead to primary and secondary breakup. The liquid fragments in surrounding gas form a dispersed multiphase flow, where droplets are evaporating and subject to turbulent dispersion. The dispersed droplets modify the gas-phase turbulence and the released fuel vapor depending on the relative speed of evaporation, mixing and combustion, burns in diffusion flames around individual droplets or clusters of droplets, or in partially premixed gaseous flames. According to the Norman Chigier experimentation the atomization of the liquid fuel is most commonly carried 
out either by injecting the fuel through small orifices at high pressure or by mixing the fuel with high pressure air or gas. The most effective atomization is achieved when thin liquid sheets are formed which subsequently become unstable and then break up to form ligaments and large drops, which then break down further into small droplets. The temperature and composition of the oxidizer influence the time scales of phase change and reaction, making a spray flame in conventional combustion different from that of a hotdiluted combustion regime. Auto-ignition of a turbulent non-premixed flame, corresponding to a transition between pure mixing and diffusive burning regimes, is encountered in many practical applications, such as a diesel engine, and is a challenge for combustion modeling. The main characteristics of the auto-ignition process of a non-premixed flame have been investigated by asymptotic analysis and direct numerical simulations. This analysis show that the ignition caused by molecular diffusion of heat and species generally does not occur under stoichiometric conditions but for the so-called most-reactive, corresponding to the maximum reaction rate, and for low values of the scalar dissipation rate v. Complex flame structures, implying both premixed and no premixed combustion regimes, are observed.

Many researchers have carried out the experimentation and numerical simulation related to the spray combustion to understand the characteristics of spray combustion in regards of stability analysis of the spray flame. Parameters which affects the stability of spray flame such as injection pressure, spray ejection velocity, spray cone angle, distribution of droplets, droplet velocity, vorticity distribution, effect of geometry of the atomizer and most important i.e. variation of the lift-off height are thoroughly studied.

S. Prakash et al. studied that the internal recirculation of liquid droplets which moves through surrounding gas towards the upstream direction of the spray burn individually at the outer periphery of the spray and form individual reaction zone called as internal group combustion.

Wlliam A. Sirignano had found that larger droplets must have greater kinetic inertia. The relative motion results in an increase of heat and mass transfer rates in the gas film surrounding the droplets; a thin boundary layer forms over the forward section of the droplet. This boundary layer also extends over a portion of the aft section. At sufficiently high Reynolds number (based upon relative velocity, droplet radius, and gas properties), separation of the gas flow occurs at the liquid interface. Since the liquid surface moves under shear, the separation phenomenon is not identical to separation on a solid sphere; for example, the zerostress point and the separation point are not identical on a liquid sphere as they are on the solid sphere.

An experimental study was conducted by G. D. Myers and A. H. Lefebvre on the influence of fuel chemistry on the flame speeds of flowing mixtures of fuel drops in air at atmospheric pressure. They found that, flame speed increases with overall fuel/air ratio in the range studied for all fuels and all test conditions. Also, dependence of flame speed on fuel/air ratio increases with increase in air velocity, SMD and decreases with increase in fuel volatility. Increase in air velocity enhances the burning velocity for any given SMD, fuel/air ratio and fuel type.

Novid Beheshti et al. devoted their work for the assessment of a new Eulerian model of two phase turbulent flows which introduced a transport equation for the average area of the liquid gas interface which was proposed by R. Borghi and co-workers to predict the effects of liquid properties and injection regimes on the atomization quality. It is shown that the model predictions are in good agreement with the observed trends for a wide range of variations of the liquid properties, such as density and surface tension, as well as the injection regimes, defined by the liquid and gas jet exit velocities.

Tie li et al. studied the droplet size distribution and evaporation characteristics of fuel spray by using laser diagnostics technique, from the analysis they have found that the droplets at outer zone of the spray exhibit larger diameter than those at inner zone under both ambient pressures 0.1 and 0.4 MPa. While this can be partially attributed to the effect of spray-induced ambient air flow, the strength of ambient air flow become small when increasing the ambient pressure from 0.1 to $0.4 \mathrm{MPa}$, indicating the strong influence of spray dynamics on the droplet size distribution. In the evaporating spray, there are higher vapor concentrations near the spray axis than at peripheral zones. At $4.0 \mathrm{~ms}$ after start of injection, spray droplets almost completely evaporate under ambient temperature $500 \mathrm{~K}$ and pressure $1.0 \mathrm{MPa}$, but there are significantly amount of fuels with equivalence ratio below 0.5 in the spray. Reduction in ambient pressure promotes the air entrainment and droplet evaporation, but lowered ambient pressure results in more fuel vapors of equivalence ratio above 1.3 along the spray axis.

Chiu et al. have observed that when liquid fuel is injected, a dense droplet cloud is formed near the nozzle exit, and the entrainment of surrounding air near the fuel nozzle is very small. As the co-flow velocity is increased, the droplets are moved to the upward direction due to gain in momentum, demand the distance between adjacent droplets increases, thus making the cloud as less dense and allowing for increased entrainment of air from surroundings.

H. Correia Rodrigues et al. carried out the experimental work on ethanol spray flame by varying the temperature of coflow stream from $1225 \mathrm{~K}$ to 1480 $\mathrm{K}$. It has been observed that the lift-off height depends on the liquid mass flow rates as well as the coflow conditions. The lift-off height is shown to increase for lower coflow temperatures and higher liquid mass flow rates. It is found that lift-off behavior depends on the 
droplet convective, vaporization and chemical time scales prior to ignition. Phase Doppler anemometry results indicate that the droplet mean size and velocity distribution close to the atomizer are not influenced temperature leads to a reduction of the local peak temperatures.

On ethanol turbulent spray flame the Marley et al. had conducted the experimental work using OH-Planar Laser Induced Fluorescence as smoke visualization techniques to investigate the reaction zone structure and effect of air entrainment on the combustion. The experimental results shows that annular air co-flow surrounds an axi-symmetric spray injector utilize a pressure-swirl atomizer to supply a hollow cone fuel spray. In the absence of a co-flowing air stream, the flame possesses a double reaction zone with an inner structure that burns intermittently with areas of local extinction occurring often at the most upstream locations near the leading edge. Also, the addition of low-speed co-flow increases the lift off height resulting in higher entrainment rates and enhanced inner zone combustion. They have reported that without co-flow, the flame exhibits a double flame structure and flame burns intermittently, and the addition of low-speed coflow lifts the flame and single flame structure burns continuously.

Dr. V. M. Reddy studied that flameless combustion technique is proven as effective method for suppression of $\mathrm{NO}_{\mathrm{x}}$ in combustion systems . To obtain flameless combustion mode in a system, the combustion products need to be re-circulate in large quantities to ensure that the flame is blown-off from the primary combustion zone. Therefore, it becomes extremely important to understand the characteristics of lifted spray flames and their blow-off characteristics. M. S. Cha studied the effect of swirling spray on the lifted flame experimentally by continuously rotating the nozzle to create the swirl flow. Results show that the lift-off height decreases linearly with nozzle rotational speed in turbulent jets. The model for swirl jets predicts that a normalized lift-off height depends solely on swirl number, and experimental results substantiate this prediction. For laminar non-premixed jets, triple flames) play an important role for flame stabilization, which consists of a rich premixed flame, a lean premixed flame, and a diffusion flame, all extending from a flame stabilization point. Increasing in demand for controlling $\mathrm{NO}_{\mathrm{x}}$ and $\mathrm{CO}$ emission from combustion of fossil fuel which causes the green house effects motivates to do the research on liquid fuel combustion.

Thus to understand the flame performance and stabilization mechanism of spray flame which will be helpful to improve the combustion process and combustion efficiency the investigation on the variation of the liftoff height of spray flame have been experimentally carried out for kerosene and diesel fuel.

The objectives of this work are:

1) To measure the liftoff height for kerosene and diesel spray flame for no coflow condition in the pressure range of 4 bar to 12 bar.
2) To measure the liftoff height for normal and preheated coflow condition i.e. velocity range of $0.1 \mathrm{~m} / \mathrm{s}$ to $0.4 \mathrm{~m} / \mathrm{s}$ and temperature range of $50^{\circ} \mathrm{C}$ to $150^{\circ} \mathrm{C}$.

3) To study the various factor responsible for stability of spray flame.

4) To study the droplet size distribution and velocity dynamics using shadography and PIV.

\section{Experimental Details}

Experimental Setup consists of different component like 1) Fuel tank 2) Coflow Chamber 3) Pressure Swirl Spray Nozzles 4) Air heater 5) Blower 6) K Type Thermocouple 7) Pneumatic Pressure Regulator 8) Voltage Variac 9) Temperature Indicating Controller etc.

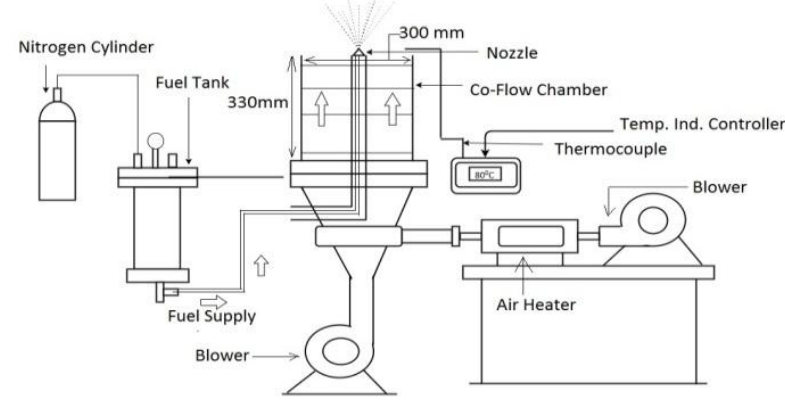

Fig.1 Schematic of Experimental Setup

Fig.1 shows the schematic diagram of lifted spray flame setup with equipment used for experimental work. Fuel tank as shown in the fig is used for storing the kerosene and diesel fuel. Properties of fuels are shown in the table1. Fuel is pressurized with nitrogen gas and it is supplied through centrally located hose pipe. The pressure in the fuel tank is varies from 4 bar to 12 bar using pneumatic pressure regulator. The volume of the nitrogen gas inside the fuel tank is $7 \mathrm{~m} 3$. The fuel is injected through the simplex danfoss fuel burner nozzle. The rated mass flow rate of nozzles are 1.87 $\mathrm{Kg} / \mathrm{hr}, 3.72 \mathrm{Kg} / \mathrm{hr}$ and $7.42 \mathrm{Kg} / \mathrm{hr}$ with a spray cone angle of $45^{\circ}$ which are calibrated at 10 bar injection pressure.

Table 1 Properties of Kerosene and Diesel

\begin{tabular}{|c|c|c|}
\hline Properties & Kerosene & Diesel \\
\hline Density & $780-810 \mathrm{Kg} / \mathrm{m}^{3}$ & $800-950 \mathrm{Kg} / \mathrm{m}^{3}$ \\
\hline Flash Point & $334 \mathrm{~K}$ & $324 \mathrm{~K}$ \\
\hline $\begin{array}{c}\text { Auto Ignition } \\
\text { Temperature }\end{array}$ & $493 \mathrm{~K}$ & $543 \mathrm{~K}$ \\
\hline $\begin{array}{c}\text { Lower Heating } \\
\text { Value }\end{array}$ & $43.1 \mathrm{MJ} / \mathrm{Kg}$ & $43.3 \mathrm{MJ} / \mathrm{Kg}$ \\
\hline $\begin{array}{c}\text { Higher Heating } \\
\text { Value }\end{array}$ & $46.2 \mathrm{MJ} / \mathrm{Kg}$ & $45.6 \mathrm{MJ} / \mathrm{Kg}$ \\
\hline
\end{tabular}

Two blowers having a capacity of $4.3 \mathrm{~m}^{3} / \mathrm{min}$ is used to supply coflow air. Heater is used to heat the air to form preheated coflow. The capacity of heater is $3 \mathrm{KW}$ which 
is mounted in $450 * 200 \mathrm{~mm} \mathrm{c} / \mathrm{s}$ mild steel box. The box is insulated with ceramic wool having the thermal conductivity of $0.34 \mathrm{~W} / \mathrm{mK}$ to prevent the heat loss. One blower is attached to heater it supplies the air to heater then heated air is circulated through gas distributor for the equal distribution of heated air and another blower allows the coflow air in exit of the coflow chamber. The perforated sheets are attached in the coflow chamber to achieve the uniform coflow velocity at axial and radial location. The velocity of coflow is measured by digital anemometer with resolution of $0.01 \mathrm{~m} / \mathrm{s}$. The range of the instruments is varies from $0-50 \mathrm{~m} / \mathrm{s}$. The $\mathrm{K}$ type rod thermocouple is used to measure the temperature of coflow air. The thermocouple is attached to temperature indicating controller.

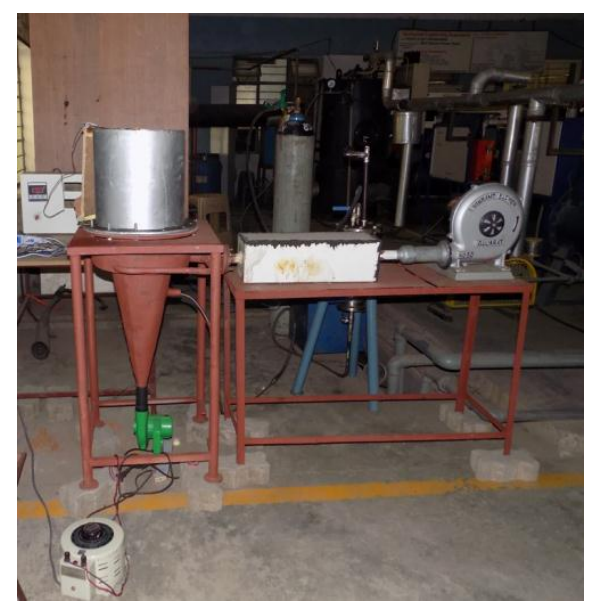

Fig.2 Actual Experimental Setup of Lifted Spray Flame

\section{Methodology}

At first the experimental work has been carried out for no coflow condition means there is no any air is supplied through coflow chamber. Before the actual experimental work the scaling is done to convert the unit distance of measuring scale to unit distance of software. After that the fuel is injected by pressurizing fuel which is stored in the fuel tank. The Spray is ignited to propagate the flame. After $10 \mathrm{sec}$ from flame propagation, multiple images have been taken by using high speed camera. These images are processed in GIMP-2 software to calculate the lift-off height. Same procedure is followed to calculate the liftoff height for normal and preheated coflow condition. The multiple images are taken for varies coflow velocity and coflow temperature. In the coflow condition air is allowed to pass through the co-flow chamber which is mix near outer periphery of the flame. The purpose of low speed coflow is for mixing of air in spray otherwise at high speed coflow the may get disturb or blow off.

\section{Results and Discussion}

a) Nozzle Calibration
Calibration is defined as the process of configuring an instrument to provide the result for the sample within an acceptable range. Calibration of the nozzle is essential because the rated mass flow rate of the nozzle is calibrated at 10 bar thus as the operating pressure is change the mass flow rate is changes. To know actual mass flow rate of nozzles at given pressure we must calibrate the nozzle for accurate result.

For this work the nozzle is calibrated by actual method from 1 bar to 14 bar pressure range. First at 1 bar pressure fuel having the $50 \mathrm{ml}$ volume is collected in the measuring flask. Time required to collect the 50 $\mathrm{ml}$ fuel is counted by using stop watch. Thus volume flow rate is calculated. This volume flow rate is converted into mass flow rate. Same procedure is followed from 2 bars to 10 bar pressure. In the literature it has been found that the nozzle was calibrated at 9 bar pressure because all the nozzles had given almost same performance i.e. the range of the average droplets size was almost same.

After the calibration of nozzle discharge coefficient have been calculated for 1 bar to 14 bar injection pressure for nozzles having the rated mass flow rate of $1.87 \mathrm{Kg} / \mathrm{hr}, 3.72 \mathrm{Kg} / \mathrm{hr}$ and $7.42 \mathrm{Kg} / \mathrm{hr}$. The discharge coefficient is calculated by using following expression.

$C_{D}=\frac{\dot{\mathrm{m}}}{A_{o} \sqrt{2 \nabla p \rho_{l}}}(1)$ [Arthur Lefebvre]

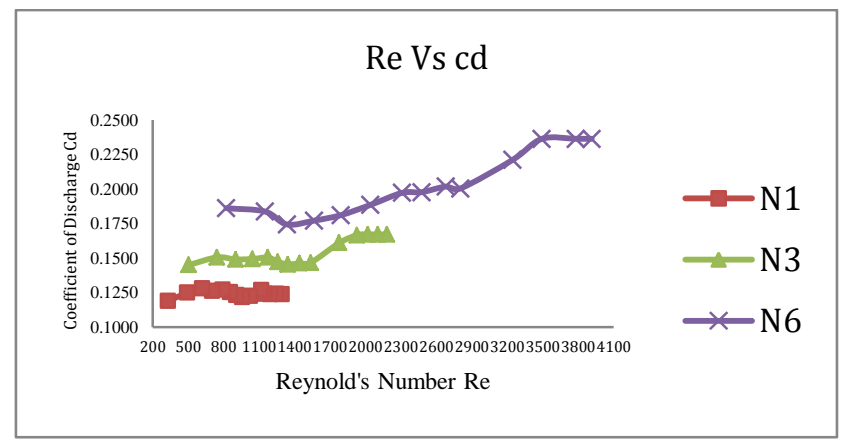

Fig.3 Variation of $C_{D}$ w.r.t. Reynolds Number

Fig.3 shows the variation of discharge coefficient with respect to Reynolds number. It has been observed from the graph that in the laminar zone the discharge coefficient is increases linearly w.r.t. Reynolds number. In the transition zone the discharge coefficient first increases and then decreases. As the turbulent zone is started the $C_{D}$ is constant w.r.t. change in Reynolds number because time rate change is very negligible thus there is no change in volume flow rate.

\section{b) LOH for No Coflow Condition}

In this case the experimentation is been carried out to measure the liftoff height of the kerosene spray flame to understand the performance of lifted spray flame for kerosene. The liftoff height is calculated for injection pressure of 4 bar, 6 bar, 8 bar, 10 bar and 12 bar. The nozzles used for atomization are simplex danfoss solid 
cone pressure swirl nozzle having mass flow rate of $1.87 \mathrm{~kg} / \mathrm{hr}, 3.72 \mathrm{~kg} / \mathrm{hr}$ and $7.42 \mathrm{~kg} / \mathrm{hr}$ which are calibrated at 10 bar injection pressure. The calibration is done for above mention nozzles from 1 bar to 14 bar injection pressure to find the mass flow rate of nozzle from 1 bar to 14 bar injection pressure.

Following are the figures which show the photographs of lifted spray flame for $\mathrm{N} 1$ and $\mathrm{N} 6$ nozzles are at injection pressure of 4 bar, 6 bar and 10 bar.
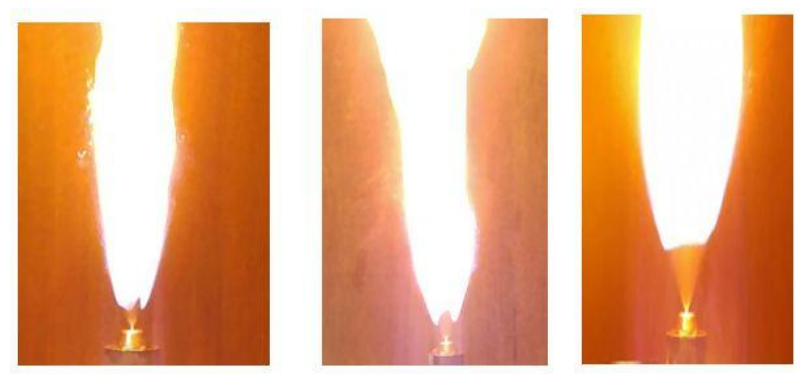

Fig.4 Photograph of Lifted Spray Flame for N1 Nozzle at 4, 6 and 10 bar Injection Pressure

As shown in the above fig.4 It has been obsereved that the flame liftoff height is grdually increases as the injection pressure is increases.

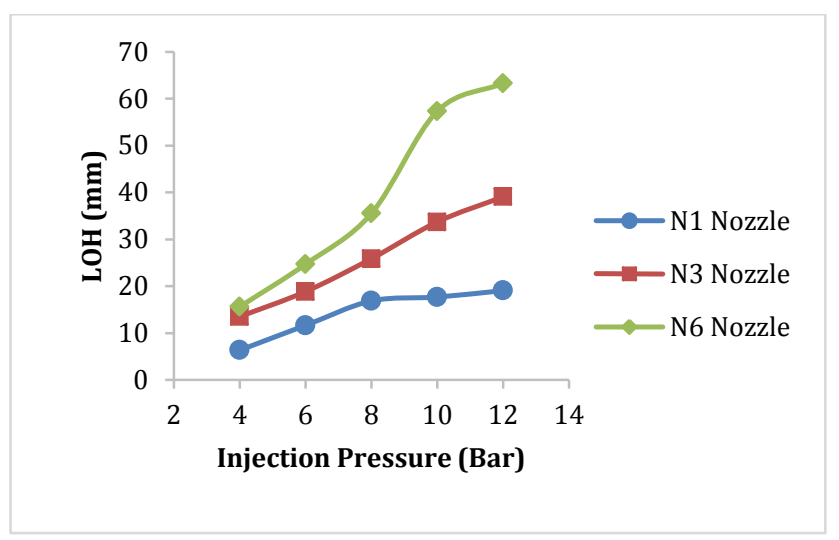

Fig.5 Injection Pressure Vs Lift-off Height for Kerosene Spray Flame

Fig. 5 shows the graph of variation of liftoff height with respect to injection pressure. It has been observed from the graph that injection pressure in directly proportional to the liftoff height because when the injection pressure is increases the mass flow rate is increases as the mass flow rate is increases momentum of droplets get increases in downstream direction. Because of the high momentum of smaller droplets at higher injection pressure the collision of droplets occurs. This collision of the droplets always in the fever of increasing in the surface tension force of droplets. Thus even though if there is formation of smaller droplet at higher injection pressure, have slightly increases the droplet diameter because of droplet cohelesence. For higher droplet diameter the weber number is i.e. surface tension force is more than external aerodynamic force. Hence the liftoff height is increases at higher injection pressure.

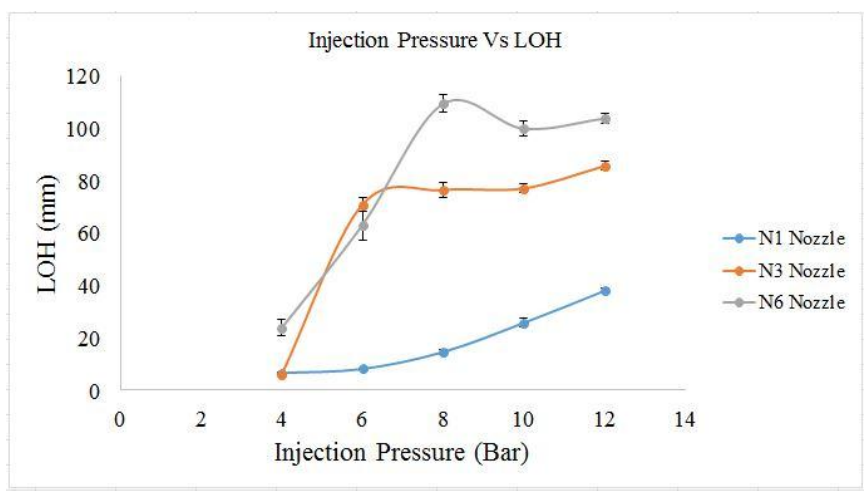

Fig.6 Injection Pressure Vs Lift-off Height for Diesel Spray Flame

It has observed form above graph which shows in fig.6. Liftoff height for diesel is more at higher mass flow rate i.e. above $3.5 \mathrm{Kg} / \mathrm{hr}$ and higher injection pressure as compared to kerosene because the density of the diesel is more than kerosene fuel thus the Webber number is less because the surface tension force is more than external aerodynamics force which causes droplets formation with larger SMD (Sauter Mean Diameter) at higher injection pressure. Also the diesel is less volatile fuel than kerosene hence it requires more time to form ignitable mixture.

\section{Conclusion}

1) Liftoff height is directly proportional to the injection pressure because as the injection pressure is increases velocity of the droplets are increases thus because of high momentum of the droplets it collides with each other. Hence small size droplets again converted into large size thus it takes more time to evaporation and burning.

2) For without coflow condition the spray is very dense at higher injection pressure i.e. distance between two droplets is more than its diameter.

3) Average liftoff height is found to be more in diesel as compare to the kerosene fuel because after the atomization external aerodynamics force on liquid sheet is less thus secondary breakup of the droplets are slow.

\section{References}

Eva Gutheil, (1992) Modeling and Simulation of Droplet and Spray Combustion Handbook of Combustion, Vol.1, pp. 205-226.

Chiu HH, Kim HY, Croke EJ.,(1982) Internal Group Combustion of Liquid Droplets Proc. Combust. Inst., pp. 971- 80.

Norman A. Chigier, (1976) The Atomization and Burning of Liquid Fuel Sprays Proc. O. Energy Combust. Sci., Vol. 2, pp. $97-114$ 
Hugo Correia Rodrigues, Mark J. Tummers, Eric H. van Veen, Dirk J.E.M. Roekaerts, (2015) Spray Flame Structure in Conventional and Hot-Diluted Combustion regime Combust. and Flame, Vol. 162, pp. $759-373$.

S. Prakash, V. A. Siringnano, (1978) Liquid Fuel Droplet Heating with Internal Recirculation Int. Journal of Heat and Mass Transfer, vol. 21 pp. 885 - 895.

W. A. Siringnano, (1983) Fuel Droplet Vaporization and Spray Combustion Theory Prog. Energy Combust Sci. Vol. 9 pp. $291-322$.

Myers GD, Lefebvre AH., (1986) Flame Propagation in Heterogeneous Mixtures of Fuel Drops and Air", Combust. Flame, pp. 193 - 210.

Beheshti N, Burluka A.A., Fairweather M., (2007) Assessment of P -Yliq Model Predictions for Air-assisted Atomization", Theor. Comput. Fluid Dyn., Vol. 21, pp. 381 - 397.

Tie Li, Keiya Nishida, Hiroyuki Hiroyasu, (2011) Droplet Size Distribution and Evaporation Characteristics of Fuel Spray by a Swirl Type Atomizer Fuel, 2011, Vol. 90 pp. 2367 2376.
Chiu HH, Lin CL., (1996) Anomalous Group Combustion of Premixed Clusters Proc. Combust. Inst., pp. 1653 - 61.

H. Correia Rodrigues, Tummer MJ, Van Veen EH, Roekaerts JEM., (2015) Effect of coflow temperature and composition on ethanol spray flames in hot-diluted coflow, International Journal of Heat and Fluid Flow vol. 51 pp. 309-323.

Marley SK, Welle EJ, Lyons KM, Roberts WL., (2004) Effect of leading edge entrainment on the double flame structure in lifted ethanol spray flames, Exp. Therm. Fluid Sci., pp. 23 31.

V. M. Reddy, (2013) Flameless Combustion with Liquid Fuel Ph.D. Thesis.

M. S. Cha Lee DS, Chung SH., (2012) Effect of swirl on lifted flame characteristics in non-premixed jets", Combustion and Flame, vol. 73 pp. 151-162. 